\title{
A AVALIAÇÃO NO ENSINO SUPERIOR: A IMPORTÂNCIA DA DIVERSIFICAÇÃO DOS INSTRUMENTOS NO PROCESSO AVALIATIVO
}

\author{
Daniela Ziolli Vito ${ }^{1}$ \\ Rosemari Pedroso Szezerbatz ${ }^{2}$
}

VITO, D. Z.; SZEZERBATZ, R. P. A avaliação no ensino superior: a importância da diversificação dos instrumentos no processo avaliativo. EDUCERE - Revista da Educação, Umuarama, v. 17, n. 2, p. 221-236, jul./dez. 2017.

RESUMO: Este artigo tem como objetivo refletir sobre a importância da diversificação de instrumentos avaliativos no ensino superior, e sua influência na qualidade da formação profissional, tendo em vista a diversidade de alunos e suas diferentes formas de aprender. $\mathrm{O}$ ato de avaliar não deve ser compreendido apenas no momento da realização das provas e testes, mas sim como um processo contínuo e que ocorre dia após dia, visando sempre à correção dos erros e encaminhando o aluno para a aquisição dos objetivos previstos. Sendo assim, a forma avaliativa funciona como um elemento de integração e motivação para o processo de ensino-aprendizagem. Isso se faz necessário à compreensão do docente sobre a importância da utilização de instrumentos diversificados de avaliação, do qual é extremamente redundante, pois, é a partir desta ideia que o mesmo obterá resultados significativos sobre o desenvolvimento dos alunos. Se tratando do ensino superior, analisar o processo avaliativo é extremamente relevante ao objetivo proposto, pois a própria legislação educacional (LDB 9394/96), contempla em seu texto a avaliação contínua e cumulativa com prevalência dos aspectos qualitativos sob os quantitativos, pois sabe-se que muitos alunos chegam ao curso superior com carência de domínios de conteúdos básicos e necessários ao desenvolvimento esperado. Para tanto é preciso elaborar estratégias de ação que possibilitem

DOI: $10.25110 /$ educere.v17i2.2017.6598

${ }^{1}$ Daniela Ziolli Vito - graduada em Pedagogia com especialização em Docência e Gestão do Ensino Superior. E-mail: dani_ziolli@hotmail.com

${ }^{2}$ Rosemari Pedroso Szezerbatz - Pedagoga, especialista em: Gestão estratégica escolar em supervisão e orientação educacional, Métodos e técnicas de ensino e Psicopedagogia.

E-mail: rosemariaps@prof.unipar.br 
a averiguação da aprendizagem concreta aos mesmos, para que possam ter assegurado a qualidade do ensino ofertado e a eficácia da formação profissional escolhida pelo aluno.

PALAVRAS-CHAVE: Avaliação; Diversificação; Ensino Superior; Instrumentos.

\section{ASSESSMENT IN HIGHER EDUCATION: THE IMPORTANCE OF DIVERSIFICATION OF TOOLS IN THE ASSESSMENT PROCESS}

ABSTRACT: The purpose of this paper is to muse on the importance of diversification of assessment tools in higher education, and their influence on the quality of professional training, considering the diversity of students and their learning styles. The act of assessment should not be understood as the time tests are taken, but rather as an ongoing process that occurs day after day, always aiming at correcting the errors and directing the student towards the achievement of the expected objectives. Therefore, the assessment structure works as an element of integration and motivation for the teaching-learning process. It requires the understanding of the teacher about the importance of using diversified assessment tools, since it is from this idea that the teacher will obtain significant results on the development of the students. In relation to higher education, an analysis of the assessment process is extremely relevant, taking into account the diversity of students and their differentiated learning styles. The Brazilian educational legislation (LDB 9394/96) contemplates the continuous and cumulative assessment, with prevalence of the qualitative aspects over the quantitative ones, since it is known that many students come to university with a lack of basic and necessary content required for their appropriate development. Therefore, actions and strategies must be developed that allow the investigation of their concrete learning, so that they can have access to quality teaching and effective professional training as chosen by the student.

KEYWORDS: Assessment; Diversification; Higher Education; Tools. 


\section{EVALUACIÓN EN LA ENSEÑANZA SUPERIOR: LA IMPORTANCIA DE LA DIVERSIFICACIÓN DE LOS INSTRUMENTOS EN EL PROCESO EVALUATIVO}

RESUMEN: Este artículo tiene como objetivo reflexionar sobre la importancia de la diversificación de instrumentos evaluativos en la enseñanza superior, y su influencia en la calidad de la formación profesional, teniendo en vista la diversidad de alumnos y sus diferentes formas de aprender. El acto de evaluar no debe ser comprendido sólo en el momento de la realización de las pruebas, sino como un proceso continuo y que ocurre día tras día, buscando siempre la corrección de los errores y encaminando el alumno para la adquisición de los objetivos previstos. Por lo tanto, la forma de evaluación funciona como un elemento de integración y motivación para el proceso de enseñanza aprendizaje. Esto se hace necesario para la comprensión del docente sobre la importancia de la utilización de instrumentos diversificados de evaluación, del cual es extremamente redundante, pues, es a partir de esta idea que el mismo obtendrá resultados significativos sobre el desarrollo de los alumnos. Tratándose de la enseñanza superior, analizar el proceso de evaluación es extremamente relevante al objetivo propuesto, pues la propia legislación educativa (LDB 9394/96), contempla en su texto la evaluación continua y acumulativa con prevalencia de los aspectos cualitativos bajo los cuantitativos, pues se sabe que muchos alumnos llegan al curso superior con carencia de dominios de contenidos básicos y necesarios para el desarrollo esperado. Para ello es necesario elaborar estrategias de acción que posibiliten la averiguación del aprendizaje concreto a los mismos, para que puedan haber asegurado la calidad de la enseñanza ofertada y la eficacia de la formación profesional elegida por el alumno.

PALABRAS CLAVE: Evaluación; Diversificación; Enseñanza superior; Instrumentos.

\section{INTRODUÇÃO}

Este trabalho é o resultado de uma de pesquisa bibliográfica desenvolvido e apresentada como requisito para conclusão do curso de especialização em Docência e Gestão do Ensino Superior, apresentado à Universidade Paranaense - UNIPAR. Teve como objetivo refletir sobre 
a importância da diversificação de instrumentos avaliativos no Ensino Superior, e sua influência na qualidade da formação profissional, tendo em vista a diversidade de alunos e suas formas de aprender. Esta investigação partiu do princípio de que o processo de avaliação requer cuidados específicos que devem levar em consideração a qualidade da transmissão do conhecimento e do processo de aprendizagem.

A primeira etapa deste estudo foi a escolha do tema, pelo qual foi considerado a importância de o docente diversificar seus instrumentos no processo avaliativo do ensino superior, por meio de metodologias e técnicas.

$\mathrm{Na}$ segunda etapa foram realizados o levantamento bibliográfico e o fichamento das referências para que a pesquisa deste projeto fosse concretizada, levando em conta importantes educadores, como Luckesi, Consolaro e Moretto. Estes teóricos foram selecionados para esta pesquisa devido à aproximação que ambos apresentam sobre os conceitos de avaliação.

Na elaboração do projeto, foi pensado o processo de avaliação no Ensino Superior, pois a diversidade de alunos e suas diferentes formas de aprender são um dos desafios da educação. No entanto, esse desafio se explicita nos cursos superiores, tendo em vista a última etapa de formação, na qual os alunos buscam a profissionalização que dará suporte para sua independência na sociedade. Com isso, os professores de cursos superiores também precisam pensar a avaliação, como um processo contínuo de pesquisa. Devem identificar e interpretar as habilidades, os conhecimentos e as atitudes dos alunos.

Diante do exposto, vale lembrar que avaliar é um processo inerente ao ser humano, porém não é uma tarefa fácil, pois ao avaliar espera-se que aconteça a obtenção dos resultados esperados sobre algo que foi proposto. Este conceito de avaliação está voltado ao cotidiano do ser humano, ou seja, de acordo com o que for estabelecido pelos sujeitos em seus afazeres.

Nesse contexto, pode-se refletir também sobre o processo avaliativo no sistema escolar, pois assim como na prática diária do indivíduo, é importante averiguar o motivo de não se alcançar o objetivo proposto. $\mathrm{Na}$ escola, também, é preciso constatar os impedimentos que ocasionaram o desvio de metas estabelecidas para o alcance dos objetivos. Sendo assim, 
a avaliação deve ser repensada sob novos parâmetros para assumir um novo papel no processo de intervenção pedagógica, em decorrência da redefinição dos processos de ensino e de aprendizagem.

Neste sentido, é válido ressaltar que a avaliação da aprendizagem em todos os níveis de ensino tem se caracterizado como um dos processos pedagógicos de extrema relevância na educação nos últimos tempos. Inicialmente visto como um mecanismo de verificação das competências desenvolvidas pelo aluno durante e ao final do processo de ensino-aprendizagem. Este tema, é revelador da competência do professor (ensino) e do compromisso e adequação da proposta (planejamento de ensino) ao projeto pedagógico do aluno (aprendizagem). Entende-se que o processo avaliativo é fundamental e se faz necessário dentro do contexto escolar, desde a educação infantil até o nível superior.

Portanto avaliar não é mensurar valores e também não significa medir competências, mas sim verificar o caminho percorrido pelo aluno ao longo do processo de aprendizagem. Com isso, a LDB 9394/96 (24, V) apresenta que avaliação deve ser "contínua e cumulativa do desempenho do aluno, com prevalência dos aspectos qualitativos sobre os quantitativos e dos resultados ao longo do período sobre os de eventuais provas finais".

Para Consolaro (2005, p.78) a avaliação é:

[..] um processo contínuo de pesquisas que visa identificar e interpretar os conhecimentos, habilidades e atitudes dos alunos, tendo em vista mudanças esperadas no comportamento, propostas nos objetivos. A avaliação gera condições de decidir sobre alternativas no planejamento e execução do trabalho do professor e da escola como um todo.

Logo, entende-se que o processo avaliativo está para além de momentos determinados como eventuais para provas, mas que ao analisar o desenvolvimento do aluno diante de cada conteúdo, cada atividade e também na oralidade devem ser observados de forma avaliativa, pois são estes que darão suporte para compreensão do professor sobre a assimilação do aluno. Para tanto, ao avaliar é preciso que o professor estabeleça critérios a serem atingidos e, com isso os alunos possam apresentar o nível de compreensão alcançado pelo mesmo. 
De acordo com Luckesi (2005), a avaliação deverá enfatizar a importância dos critérios e instrumentos utilizados pelos professores, pois ela não poderá ser praticada apenas sob dados inventados, ou seja, deve ir se modificando de acordo com a necessidade de alunos e professores.

Essa preocupação pode ser percebida em todos os níveis de ensino, porém terá como foco neste estudo somente o Ensino Superior.

\section{O PROCESSO AVALIATIVO NO ENSINO SUPERIOR}

De acordo com Vasconcelos (1998), ao pesquisar a história da educação no que tange a avaliação, entende-se que o conceito de avaliação desencadeia discussões e reflexões ao longo do tempo. É um tema que requer compreensão diante da sua abrangência, pois desde os tempos primitivos, a avaliação apresenta divergência sobre sua compreensão e ao mesmo tempo ratifica a classificação entre as pessoas.

Para Feldmann (2009), essa ideia vem desde os primórdios, que selecionava os jovens indígenas por meio da realização de testes de aptidão para a sua passagem à vida adulta. Os jovens eram avaliados mediante os costumes de suas tribos, sendo que aqueles que não demonstrassem resultados satisfatórios no domínio de instrumentos e nas habilidades de caça e pesca não poderiam acompanhar seus mestres.

$\mathrm{O}$ autor ainda ressalta que nos séculos XIX e XX, a avaliação surge em testes específicos e padronizados que apresentavam o nível de inteligência das pessoas, porém, no decorrer do tempo os testes foram substituídos por outros meios avaliativos, em que os aspectos diferenciados que cada pessoa apresentava na elaboração do conhecimento começaram a ser considerados.

Somente na década de 30 é que o termo avaliação educacional é levado em consideração devido aos motivos de insuficiência de desempenho apresentado por boa parte dos alunos. Com isso, a responsabilidade foi atribuída às escolas, salientando a sua eficácia no processo de ensino.

Neste sentido, vale ressaltar que o desempenho de cada pessoa é determinante para o sistema social, pois a sociedade de cada época requer a formação de indivíduo que atenda a sua necessidade e, para tanto, é preciso primar pela formação de pessoas que demonstrem os conhecimentos necessários ao desenvolvimento político, econômico e social. 
É nessa perspectiva que a sociedade contemporânea percebe a avaliação como um processo de construção e possibilidades de avanço e desenvolvimento do indivíduo, pois, o sistema educacional atual dispõe sobre a importância do desenvolvimento crítico e reflexivo do ser humano.

Assim, vários autores abordam a discussão sobre este tema, levando em consideração a importância do assunto na formação de professores, tendo em vista a sua ação diante da realidade profissional.

De acordo com Luckesi (2005), a avaliação deve ser utilizada como diagnóstico que possibilite a intervenção docente visando à melhoria da aprendizagem do aluno. Neste sentido, é importante que o docente contribua com o avanço do aluno por meio da utilização de instrumentos avaliativos diversificados, pois se trata de uma ação pedagógica que constitui um ato dialógico do qual envolve ambas as partes.

$\mathrm{O}$ autor ainda ressalta que o modelo avaliativo do século XXI ainda apresenta resquícios do século XVII, em que a predominância da avaliação primava pelo modelo classificatório destacando a prevalência dos aspectos quantitativos por meio das notas e memorização, com isso não considerava o avanço gradativo do aluno. Este modelo primava pela ratificação da burguesia na sociedade brasileira.

Sobre este assunto, Consolaro (2005) parte do princípio proposto pelos objetivos que devem estar entrelaçados com a avaliação, visando ao desenvolvimento dos alunos e primando pela qualidade do avanço individualizado. Para tanto, é preciso levar em consideração a importância do planejamento e a execução do trabalho docente em prol da intenção proposta pelo professor.

Dessa forma, Moretto (2002) salienta que a avaliação da aprendizagem deve ter um sentido amplo, pois deve ser feita de formas diversas, com a utilização de instrumentos variados, desmistificando que a única forma de avaliar o aluno seja por meio do instrumento prova. Por esse motivo, a avaliação da aprendizagem também precisa estar em consonância como a forma de ensinar e, esta forma diz respeito à ação docente que, por sua vez deve primar pelos diversos métodos utilizados pelos professores.

O autor ainda destaca que a aprendizagem é um processo interior do aluno, em que os indicadores externos sinalizarão os aspectos neces- 
sários a serem considerados, pois devem ser interpretados pelos professores, levando em consideração que nem sempre a interpretação docente corresponde ao pensamento real do aluno. Com isso, é preciso considerar a possibilidade da avaliação ser pensada sob novos parâmetros, em que o professor assume o papel de mediador e realiza a intervenção pedagógica, redefinindo os conceitos a serem assimilados pelo aluno. Assim:

A avaliação é parte integrante do ensino e aprendizagem, o ensinar, um dia, já foi concebido como o transmitir conhecimentos prontos e acabados, conjunto de verdades a serem recebidas pelos alunos, gravadas e desenvolvidas na hora da prova. Nessa visão de ensino, o aprender tem sido visto como gravar informações transcritas para um caderno (cultura cadernal) para devolve-las da forma mais fiel possível ao professor na hora da prova. (MORETTO, 2002, p.94)

Diante do exposto e perante a discussão dos autores acima citados compreende que a avaliação é um processo que precisa ser analisado minuciosamente tendo em vista que o seu resultado implica em aspectos primordiais do futuro do aluno, pois poderá provocar mudanças no caminho percorrido por ele.

Ao refletir sobre esse assunto compreende-se que por ele do objetivo principal do texto, pode-se refletir sobre a importância da diversificação dos instrumentos avaliativos no ensino superior, e sua influência na qualidade da formação profissional, tendo em vista a diversidade de alunos e suas diferentes formas de aprender.

Neste sentido, se faz necessário enfatizar a importância da utilização de instrumentos diversificados que possam proporcionar o desempenho dos alunos sobre cada conteúdo trabalhado ao longo do bimestre. Cabe ao professor elaborar estratégias de ação e instrumentos que oportunizem a expressão do aluno diante do que foi proposto.

Vale destacar que a avaliação deve começar na elaboração dos objetivos propostos diante de cada conteúdo a ser trabalhado e, com isso, o instrumento a ser utilizado deve ter coerência com a proposta de trabalho docente. Cada instrumento deve levar em consideração o tipo de aprendizagem ao qual se detém o aluno, pois como já foi apresentado neste texto cada indivíduo tem sua forma diferenciada de aprendizagem ten- 
do em vista a diversidade cultural e o meio em que o mesmo está inserido. Com isso, muitos professores ainda se deparam com a inquietação no que tange a avaliação, pois:

A avaliação da aprendizagem é angustiante para muitos professores por não saber como transformá-la em um processo que não seja uma mera cobrança de conteúdos aprendidos "de cor", de forma mecânica e sem muito significado para o aluno. Angustia por ter que usar um instrumento tão valioso no processo educativo, como recurso de repressão, como meio de garantir que uma aula seja levada atermo com certo grau de interesse. (MORETTO, 2002, p.93).

Nesta perspectiva compreende-se que a avaliação ainda inquieta muitos professores, tendo em vista a subjetividade do assunto e a predominância deste conceito que se encontra enraizada na formação do professor. São essas aflições que levam muitos professores a reproduzirem os modelos avaliativos dos quais eles um dia fizeram parte.

Ao observar as discussões dos autores já elencados, é possível notar que as mesmas preocupações estão presentes. Para eles a importância de se levar em consideração os caminhos diversificados na elaboração de novos conceitos, assim como, a compreensão e a ação diferenciada do professor nos aspectos avaliativos, é que resultarão na qualidade do processo.

O docente não precisa saber decorado o conhecimento, mas necessita saber onde está a informação e como resgatá-la assim que for necessário. Muitas vezes, o docente lê anotações, artigos, livros e até projeta textos em formas de slides ou projeções em transparências e multimídias, porém, seus instrumentos avaliativos acabam se resumindo em provas objetivas e dissertativas.

Dessa maneira que entram as técnicas e metodologias para diversificar o processo avaliativo no Ensino Superior, tendo em vista a diversidade e as necessidades diferenciadas de cada aluno universitário, pois a cada ano cresce o número de alunos que apresentam carências na aprendizagem, e com isso requerem mecanismos distintos.

A avaliação da aprendizagem tem sido um tema polêmico e angustiante no âmbito escolar. Esta preocupação perpassa o nível funda- 
mental e médio e chega ao nível superior desencadeando dúvidas e conceitos diferenciados entre os professores. Esta ansiedade se dá por motivo de chegar aos bancos das universidades, alunos oriundos de sistemas educacionais diferenciados e com conceitos distintos de avaliação.

Uma das causas emergentes que englobam a avaliação está atrelada ao domínio de conhecimentos básicos que o aluno deve apresentar ao ingressar no Ensino Superior, e que não atende à expectativa do corpo docente. Neste sentido, é nítida a fragilidade da qual apesenta-se o perfil de muitos universitários e, com isso, instiga a preocupação dos professores, principalmente diante do processo avaliativo.

Por conseguinte, vale a pena pensar no processo de avaliação, juntamente com todo o processo da educação superior, servindo às atuações enquanto docentes e responsáveis pela formação profissional das futuras gerações, pois para Consolaro a avaliação:

[..] tem por premissa básica um processo contínuo durante todo o desenrolar da disciplina ou curso e permite diagnosticar e controlar o processo de ensino-aprendizagem, redirecionando-o quando necessárias e detectadas necessidades de mudanças. A avaliação propicia ao professor, entre outras coisas, uma verdadeira retroalimentação (CONSOLARO, 2005, p.80).

Portanto, ao elaborar a avaliação o docente deve refletir sobre algumas questões básicas.

- A avaliação não é sinônimo de julgamento, a explicitação dos critérios antes do processo começar faz total diferença, pois a mesma deve estar voltada para desempenho do aluno e não para a pessoa em si.

- O docente deve ter coerência com seus objetivos, ou seja, checar o que foi proposto no planejamento didático, principalmente em seus objetivos estabelecidos. A coerência deve sempre existir entre o proposto e o exigido.

- Através da explicitação dos critérios, deve cumprir com o explicado no início da disciplina ou do curso, sem mudar regras no meio do caminho. Nas aulas e atividades práticas, os objetivos e os critérios de avaliação de cada item devem ficar claros. 
- Faz parte do papel do docente também explicar com antecedência o que é importante e o que será revelado na avaliação, pois explicar claramente estes critérios é uma questão de coerência.

- O aluno é aliado e não adversário do professor, assim, as perguntas não devem ser feitas para pegá-los e, sim induzir a pensar e checar seus conhecimentos. Deve-se evitar notas de rodapé, o uso de palavras desconhecidas e não explicadas ou utilizadas em aula.

- O professor deve procurar adequar os questionamentos com o conteúdo programático, sem exigir coisas obscuras, controvertidas e não valorizadas nas aulas. Deve também distribuir as questões de forma mais ou menos uniforme no conteúdo ministrado, enfocando todas ou a maioria das alas ministradas.

- $\quad \mathrm{Na}$ avaliação, pode-se utilizar testes ou questões dissertativas, porém, essas avaliam além do conhecimento, a forma de expressão, a habilidade de escrever e o senso de organização do aluno. Nos testes, mesmo nos bem elaborados, o raciocínio tende a ser direto e o aluno não desenvolve o senso de comunicação e organização.

- A prova dissertativa deve ser formulada com clareza, em que deve ser mencionada uma habilidade mental que se deseja que o aluno demonstre. Pode-se solicitar que o aluno relacione, comente, discorra, diferencie, sintetize e argumente sobre determinado assunto. A prova dissertativa não pode restringir-se à repetição do que foi dada em aula, mas exigir o raciocínio mental envolvendo organização de ideias, clareza de expressão, aplicação prática de conhecimentos, etc.

Diante do exposto, compreendemos que a avaliação não se limita apenas aos mais variados tipos de prova. A atividade diária pode e deve ser avaliada de forma sistemática; cada trabalho feito em aula prática deve ser analisado e avaliado. Mas, deve sempre ser lembrado que os critérios precisam ser claros, objetivos e explicativos no roteiro da disciplina ou curso.

Além das perguntas dissertativas e dos testes há vários outros 
modelos de avaliação utilizando-se de questões certo e errado ou verdadeiro e falso, questões de completar lacunas, de correlacionar, corresponder ou associar duas colunas de respostas, interpretação de textos, ordenações crescentes ou decrescentes, identificação e figuras, objetos ou peças, questões sobre um determinado problema e pedir possíveis soluções, etc.

A avaliação representa um processo contínuo e pode ser diário, por unidade de ensino, mensal ou bimestral, dependendo muito das regras da instituição, da carga horária, da distribuição no tempo desta carga horária e da complexidade do conteúdo programático.

As avaliações diárias acabam sendo cansativas para os alunos, pois por mais que seja conscientizado, essa cultura implica no estresse emocional quando se diz prova ou avaliação. O ideal está em avaliar cada unidade de ensino, ou seja, o conjunto de temas e aulas que guardam relação entre si e geraria avaliações a cada 20-25 dias.

A oportunidade de autoavaliação por parte do aluno está cada vez mais tomando forma dentro da sala de aula. Ao valorizar a prática em que o aluno deve aprender a pensar sozinho, em um processo de avaliação, momentos de autoavaliação devem ser criados e valorizados. Representam formas de desenvolvimento da autocrítica, do poder de análise e de expressar sentimentos de autoconfiança, segurança, autoestima e humildade! Porém, a autoavaliação também requer estabelecimento de regras e critérios explicitados claramente.

De acordo com Consolaro (2005, p.83), alguns exemplos de perguntas efetuadas em uma autoavaliação, na qual o aluno responde: sim, parcialmente e não:

- Encontrei dificuldades no desenrolar da disciplina ou na unidade de ensino?

- Fiquei interessado pelo assunto e por isso estudei o suficiente?

- Aumentei os meus conhecimentos e mudei alguns conceitos anteriores?

- Cumpri com as tarefas e exercícios exigidos no tempo oferecido?

- Atendi às convocações do professor e colaborei quando solicitados?

- Participei de discussões e apresentei sugestões que contribu- 
íram para com o rendimento do grupo?

- Espero obter nesta autoavaliação o conceito que escolherei entre ótimo, muito bom, bom, regular e fraco.

A prática de avaliação do professor pelos alunos tem se popularizado cada vez mais, mas há de se ter cuidados na elaboração dos questionários e, principalmente com o momento desta avaliação. Logo após, o término do curso pode não ser um momento; a tensão das provas finais pode influenciar fortemente esta avaliação do professor e da sua disciplina. Talvez no início do próximo ano letivo fosse o momento ideal ou o primeiro momento; o final do curso de graduação, um segundo momento muito interessante, pois adquiriu uma visão de conjunto e pode avaliar melhor o desempenho do professor. Mas, tão interessante seria aluno avaliar o professor após um a três anos de formado, quando já desempenha suas funções como profissional da área escolhida.

A avaliação do professor feita pelos alunos, independentemente do momento em que foi realizada, induz reflexões e melhoria no desempenho do professor para as próximas turmas.

De acordo com Antunes (2001, p.9), as técnicas de dinâmica de grupo podem servir de ótimo instrumento de avaliação para o professor, pois auxiliam na aplicação em qualquer disciplina curricular ou em atividades que visem despertar o espírito crítico e a socialização do aluno. Segundo o autor, essas técnicas são válidas para trabalho com estudantes de um conteúdo específico, que visam o despertar do educando para valores, raramente vivenciados no conteúdo curricular das disciplinas.

$\mathrm{O}$ autor ainda destaca que as técnicas pedagógicas, no geral, priorizam o trabalho do professor em sala de aula. As técnicas ludopedagógicas são fundamentalmente, mas não exclusivamente, preparadas para o desenvolvimento psicomotor. Já as técnicas de sensibilização, envolvem finalidades e que integram os objetivos das anteriores. São de grande valia em programas de orientação profissional ou em atividades de integração social do aluno ou do profissional.

Diante do exposto, vale destacar que essas técnicas devem ser aplicadas quando se busca estabelecer na instituição, bases definitivas da formação ou se pretende alcançar, quando os docentes envolvidos no processo demonstram um estado de espírito que aceitem inovações como resposta de conhecer melhor essas técnicas, e por fim, quando se acredita 
que uma técnica, seja ela qual for, não representa uma 'magia' capaz de educar e avaliar pessoas e em alterar seus comportamentos, mas sim uma estratégia educacional válida na medida em que se insere em todo um processo, com objetivos claramente definidos.

Vale destacar ainda que:

A aplicação de qualquer técnica pressupõe que os envolvidos estejam constituídos em grupos, quatro a dez elementos dependendo do número total de participante envolvidos, e que existam fatos científicos ou experiências a conhecer, avaliar ou investigar. Considerando essas propostas, existem algumas técnicas específicas para o conhecimento, outras para a avaliação e algumas para a investigação; ainda que, na maior parte das vezes, a mesma técnica de avaliação fixe informações científicas e, como decorrência natural, instigue o participante a investigar outros fatos. (ANTUNES, 2001, p.19).

Sendo assim, o conhecimento adquirido por meio dessas técnicas é obtido por meio de fatos e experiências.

\section{CONSIDERAÇÕES FINAIS}

Durante o estudo inicial pelo qual foi decidido o assunto deste trabalho e elaborado o projeto de pesquisa, levou-se em conta a angústia da maior parte dos alunos pelos métodos utilizados pelos seus professores no processo de avaliação do Ensino Superior. Ao pensar neste processo, pode-se entender que surgem dúvidas e problemas muito intensos.

Alguns documentos norteadores do processo de formação humana, assim como a legislação educacional, apresentam a necessidade da formação do homem em sua plenitude. Um homem que atenda à demanda da sociedade, e que saiba conviver, agir, fazer, pensar e exercer sua função social e política. Formação esta que requer total responsabilidade de instituições educacionais e principalmente, dos docentes, pois são eles que acompanham o desenvolvimento habitual do aluno e trabalham em prol desta formação.

Ao analisar o processo avaliativo dentro do Ensino Superior, pode-se perceber a falta de interesse dos alunos diante deste processo, e a 
falta de entendimento sobre a importância da avaliação. Pode-se perceber também que alguns professores não utilizam instrumentos diversos por falta de tempo em elaborar, e até pela ausência dos conhecimentos de técnicas diferenciadas, entre outros.

Diante do exposto, há necessidade da diversificação dos instrumentos avaliativos, no sentido em que o docente deve ofertar possibilidades diferenciadas que estimulem os alunos a demonstrarem o conhecimento adquirido sem apresentar o medo que carregam da prova. No entanto, é notável que o tema avaliação é muito comentado entre professores, e até fora da rotina educacional, porém, falar é muito comum, mas aplicar o conhecimento acaba se tornando uma incógnita.

Mesmo diante de todas estas incógnitas geradas no processo avaliativo, há de se pensar que muitos professores são resistentes em assumir suas limitações e não buscam auxílio, prejudicando a aprendizagem, deixando de atingir os objetivos propostos.

Vale lembrar que avaliar não é simplesmente atribuir conceitos e mensurar valores. Avaliar é compreender em que situação se encontra o processo de desenvolvimento de cada aluno e fazer as devidas intervenções necessárias para que o mesmo possa entender o que se espera.

Vale ressaltar também que o docente ao avaliar o aluno, não deve dar nota a fim de que o aluno passe de ano. A avaliação deve ser a problematização do aluno de todas as formas com instrumentos diversificados em que possam colaborar com a compreensão do professor/a se o/a aluno/a conseguiu avançar no processo de desenvolvimento.

Faz-se necessário analisar que o desenvolvimento do aluno não pode estar considerado em decorar fórmulas, ou reproduzir o que aquele autor ou o que aquele livro disse sobre determinado assunto.

Os docentes devem entender que ao avaliar seus alunos, estão avaliando o seu próprio trabalho. Da mesma maneira que os alunos também devem compreender que a avaliação não pode ser de momento, uma vez que os conteúdos que são avaliados precisam ser compreendidos e internalizados por eles.

Portanto, pesquisar sobre avaliação é muito mais que adquirir conceitos pré-estabelecidos. É, sobretudo, obter consciência crítica e verdadeira dos aspectos inerentes ao processo de ensino e aprendizagem como cooperantes na produção do conhecimento. 


\section{REFERÊNCIAS}

ANTUNES, C. Manual de técnicas de dinâmica de grupo de sensibilidade de ludopedagogia. Petrópolis: Editora Vozes, 2001.

BRASIL, Senado Federal. Lei de Diretrizes e Bases da Educação Nacional: $n^{\circ}$ 9.394/96. Brasília:1996.

CONSOLARO, A. O "ser" professor: arte e ciência no ensinar e aprender. 4. ed. - Maringá: Dental Press, 2005. 240 p.

FELDMANN. M. G. (Org). Formação de professores e escola na contemporaneidade. São Paulo: Cortez, 2004.

GADOTTI, M. ROMÃO, J. Autonomia da escola: princípios e propostas. São Paulo: Cortez, 2004.

HOFFMAN, J. Avaliação: mito \& desafio. Porto Alegre: Educação e Realidade, 1993.

LUCKESI, CIPRIANO C. Avaliação da aprendizagem escolar. São Paulo: Cortez, 2005.

MORETTO, V.P. PROVA: um momento privilegiado de estudo não um acerto de contas. Rio de Janeiro: DP\&A, 2002.

VASCONCELOS, C. Avaliação da aprendizagem: práticas de mudança. São Paulo: Libertad, 1998.

Recebido em: 05/07/2017

Aprovado em: 24/07/2017 